African J. Biol. Sci., 17 (1): 63-72 (2021)

ISSN 1687-4870

e- ISSN 2314-5501 (online)

www.ajbs.journals.ekb.eg

E.mail: aasdjournal@yahoo.com

\title{
Comparative study on the effectiveness of gum arabic Acacia senegal and Moringa oleifera extracts on prevention of peptic ulcer in the experimental rats
}

\author{
Ekbal M.M. Saleh, El-Sayeda G.E. El-Sahar and Aisha F.M. Elnadi* \\ Home Economic Department. Faculty of Specific Education, Ain Shams Univ., Cairo, Egypt \\ dr.ekbal.mahmoud@sedu.asu.edu.eg \\ Dr_sayeda2015@yahoo.com \\ *Aishaelnadi@yahoo.com
}

Received: January 17, 2020; Accepted: Feb.28, 2021; Available online: March. 2, 2021

\begin{abstract}
Peptic ulcer is one of the world's major gastrointestinal disorders and affecting $10 \%$ of the world population. An estimated 15000 deaths occur each year as a consequence of peptic ulcer. The cost of treatment for peptic ulcers is expensive and has side effects. So, it is necessary to conduct research to develop new therapeutic agents for the treatment of stomach ulcers. It is known that medicinal plants are important sources of biologically active molecules with the genetic ability of anti-ulcer. This study aims to evaluate the effectiveness of using gum arabic Acacia senegal and Moringa oleifera extracts on treatment of peptic ulcer in the experimental rats. Fifty rats were divided into 8 groups (6/each group). One group feeds the basic diet only (positive control group, $\mathrm{G}+$ ). The remaining 44 rats were infected by aspirin solution to induce peptic ulcer in their stomach. One group of these rats feeds the basic diet only (negative control group, G-). Three groups G1, G2 and G3 feed on the basic diet + gum arabic extract $(500,1000$ and $1500 \mathrm{mg} / \mathrm{kg}$ of rat weight). The other groups G4, G5, G6 feed the basic diet+ Moringa oleifera extract (800, 1000 and $1200 \mathrm{mg} / \mathrm{kg}$ of rat weight). At the end of the experiment ( 6 weeks), rats were fasted for 12 hours before slaughtering, blood samples were collected to obtain the serum, the stomach was separated for examination and gastric juice was collected to determine the (PH).

The results indicated that rats in groups G6 and G3 had the highest increase in number of their WBC and in their HP as compared to $(\mathrm{G}+)$.

Histological study revealed the absence of histopathological changes in G3 and G6 , while other groups showed mucosal vascular congestion and submucosal edema with inflammatory cell infiltration.
\end{abstract}

Key words: Gum Arabic, Acacia senegal, Moringa oleifera, peptic ulcer, risk factors.

\section{INTRODUCTION}

Peptic ulcer disease (PUD) occurs due to a breakdown of the gastrointestinal tract's mucosal defense particularly at a site where the mucosal epithelium is exposed to acid and pepsin (Akomas, et al., 2014; Hemamalini, et al., 2012; Osim, 2002). It affects 4 million people worldwide annually (Zelickson et al., 2011). The most common symptoms are waking at night with the middle or upper abdominal pain that improves with eating.
Also include belching, vomiting, heartburn, bloating, weight loss, or poor appetite (Najm, 2011). Complications may include bleeding, perforation, and blockage of the stomach. Bleeding occurs in as many as $15 \%$ of people (Milosavljevic et al. 2011). In severe cases, symptoms can include dark or black stool (due to bleeding), vomiting blood (that can look like "coffee-grounds"), weight loss, perforation (a hole through the wall of the stomach) and gastric outlet obstruction from swelling or scarring that 
Ekbal M.M. Saleh et al.

blocks the passageway leading from the stomach to the small intestine.

The treatment of chronic peptic ulcer disease varies depending on the etiology of the ulcer (HP or Non-steroidal antiinflammatory drugs, whether the ulcer is initial or recurrent, and whether complications have occurred.

Plants are a rich resource used for centuries to cure various ailments. The literature revealed that many medicinal plants and polyherbal formulations are used for the treatment of ulcer. The first effective drug against gastric ulcer was carbeno-xolone, discovered as a result of research on a commonly used indigenous plant Glycyrrhiza glabra. Sasmal et al. (2007) indicated that cabbage previously employed as an antiulcer agent in folk medicine and it acts by enhancing the gastric mucosal strength.

Gum Arabic (GA) Acacia Senegal is reported to prevent development of indomethacin induced gastric ulcers in rats (Gohar and Zaki, 2014). Also, it is reputed in Arabian medicinal practices to be useful in treating patients with chronic renal failure. Additionally, GA is reported to possess antioxidant (Trommer and Neubert, 2005; Gado and Aldahmash, 2013).

Leaf extracts of Moringa oleifera showed gastric ulcer healing effect in acetic acid-induced chronic gastric ulcers. The acetone extract and methanol extract of the leaves produced gastric antisecretory effect in pylorus-ligated rats and showed gastric cytoprotective effect in ethanol-induced and indomethacininduced gastric ulcers. Leaf extracts also produced a significant reduction of stressinduced gastric ulcers. None of the extracts of the fruits showed any significant antiulcer effect. It was concluded that leaves of Moringa oleifera increase healing of gastric ulcers and also prevent the development of experimentally induced gastric ulcers in rats (Devaraj et al., 2007).
This study aim aimed to evaluate the effect of using extracts of each of gum arabic and Moringa oleifera on treatment of peptic ulcer in rats.

\section{MATERIALS AND METHODS Materials}

Animals: 50 male albino rats (160 to $185 \mathrm{~g}$ ) were obtained from the animal house at the Agricultural Research Centre in Giza (ARC).

Herbs: Gum arabic" Acacia senegal" $(1 \mathrm{~kg})$ and Moringa oleifera $(1 \mathrm{~kg})$ were purchased from HARRAZ "Agricultural seeds, spices and medicinal plants" from Cairo Governorate, Egypt.

Drugs: Aspirin (Aspirin Revo at a concentration of $320 \mathrm{mg}$ ) was purchased from pharmacies. Vitamins and mineral salts were purchased from "Al Gomhoreya Company for Chemicals"-Cairo-Egypt.

\section{Methods}

\section{Preparation of aqueous extract}

The aqueous extracts of Gum Arabic and Moringa oleifera were prepared using $10 \mathrm{~g}$ dried material $/ 100 \mathrm{ml}$ distilled water and boiling for $5 \mathrm{~min}$ at $100^{\circ} \mathrm{C}$. Then they were filtrated, concentrated at $50^{\circ} \mathrm{C}$ under reduced pressure using a Rota vapor. The extracts were kept at $-15{ }^{\circ} \mathrm{Cuntil}$ it was used in the experiment (Kassi et al., 2004).

\section{Preparation of basal diet}

The basal diet was formulated to meet recommended nutrients levels for rats according to Hegested et al. (1941) as shown in Table (1).

Table (1): Composition of the Basal Diet.

\begin{tabular}{|l|l|}
\hline Ingredients & Weight \\
\hline Casein & $15 \%$ \\
\hline Corn oil & $10 \%$ \\
\hline Cellulose & $5 \%$ \\
\hline Vit. Mixture & $1 \%$ \\
\hline Salt mixture & $4 \%$ \\
\hline Corn starch & $65 \%$ \\
\hline Total & $100 \%$ \\
\hline
\end{tabular}




\section{Comparative study on the effectiveness of gum arabic Acacia senegal and Moringa oleifera extracts on prevention of peptic ulcer in the experimental rats}

\section{Experimental design}

All Animals were fed on the prepared basal diet. Water is performed all the time. Rats were maintained under healthy conditions of humidity and temperature $22 \pm 2^{\circ} \mathrm{C}$ and maintained in air-conditioned room on a $12 \mathrm{~h}$ light/dark cycle. They were acclimatized under the test condition for a week before treatments.

After acclimatization period, 50 rats were divided into 8 groups (6/group). Negative control group fed on the basal diet. Each of rats in the other groups were induced gastric ulcer by giving orally $4 \mathrm{ml}$ aspirin solution on an empty stomach daily for a week according to Al Dalian et al. (2008) method. Sample of 2 rats from each group was taken to examine the stomach for gastric ulcers according to Agrawal et al. (2000) method.

Groups G1, G2 and G3 fed the basic diet + gum arabic extract (500, 1000 and $1500 \mathrm{mg} / \mathrm{kg}$ of rat weight), respectively. While groups G4, G5 and G6 were fed the basic diet + Moringa oleifera extract (800, 1000 and $1200 \mathrm{mg} / \mathrm{kg}$ of rat weight), respectively.

The experiment lasted for 6 weeks, during which the daily intake of the food was calculated by weight calculation once a week. At the end of the experiment, all rats were sacrificed after using an overdose of diethyl ether and their stomachs removed and washed by saline. The following items were investigated:

1- White Blood Cells (WBC) and Lymphocytes: Blood samples from each rat were collected separately count of WBC and lymphocyte.

2- pH and volume of gastric juice: Gastric juice was collected in a test tube to measure its volume and the $\mathrm{pH}$ of the stomach juice was determined using the $\mathrm{pH}$ meter (h19021). Gastric juices were centrifuged at $500 \mathrm{rpm}$ for 5 minutes, then separated and measured volume by graduated cylinder.

\section{Histopathological examination}

The stomachs of the scarified rats were taken and immersed in $10 \%$ formalin solution. The fixed specimens were then trimmed, washed and dehydrated in ascending grades of alcohol. Specimens were then cleared in xylem, embedded in paraffin, sectioned at 4-6 microns thickness and stained with Heamtoxylin and Eosin stain for examination of the stomach as described by Carleton (1979).

\section{Statistical analysis}

The obtained results were expressed as Mean \pm SE. Data were evaluated statistically using one-way analysis of variance (ANOVA). Significant difference between means was estimated at $p<0.05$ (STATSOFT, 2006).

\section{RESULTS}

1- Effect of gum arabic and Moringa oleifera extracts on WBC and lymphocytes in rats

WBC and lymphocytes in rats given orally gum arabic extract at doses 500, 1000 and $1500 \mathrm{mg} / \mathrm{kg}$ demonstrated significant increase in those of G1, G2 and G3 when compared with positive control group $\left(\mathrm{G}^{+}\right)$with the highest significant increase was in G3. On the other hand, WBC and lymphocytes were significantly decreased in rats of G1, G2 and G3 as compared with negative control group $\left(\mathrm{G}^{-}\right)$with lowest one recorded at $\mathrm{G} 3$.

The results of the effect of using Moringa oleifera extract at doses of 800 , 1000 and $1200 \mathrm{mg} / \mathrm{kg}$ orally on WBC and lymphocytes in rats of G4, G5 and G6 showed significant increase in G4, G5 and G6 when compared with positive control group $\left(\mathrm{G}^{+}\right)$, while there was a significant decrease in G4 and increase in G5 and G6 as compared with negative control group $\left(G^{-}\right)$. The highest significant increases in 
Ekbal M.M. Saleh et al.

WBC and lymphocytes were found in G6. As shown in Table (2).

Table 2: Effect of gum arabic and Moringa oleifera extract on WBC and lymphocytes in rats.

\begin{tabular}{|l|c|c|}
\hline \multirow{2}{*}{ Treat } & WBC count & Lymphocytes count \\
\cline { 2 - 3 } & Mean \pm SD & Mean \pm SD \\
\hline$\left(\mathrm{G}^{+}\right)$Control Positive & $3,167.34 \mathrm{i} \pm 95.11$ & $0.58 \mathrm{~g} \pm 0.02$ \\
\hline $\left.\mathrm{G}^{-}\right)$Control Negative & $9,462.88 \mathrm{bc} \pm 333.96$ & $3.86 \mathrm{~b} \pm 0.14$ \\
\hline G1 (feed GA 500mg/kg weight of rat) & $6,601.81 \mathrm{~h} \pm 232.99$ & $2.76 \mathrm{f} \pm 0.10$ \\
\hline G2 (feed GA 1000mg/kg weight of rat) & $7,999.63 \mathrm{fg} \pm 776.91$ & $3.35 \mathrm{~d} \pm 0.33$ \\
\hline G3 (feed GA 1500mg/kg weight of rat) & $9,133.26 \mathrm{~cd} \pm 274.26$ & $3.73 \mathrm{bc} \pm 0.11$ \\
\hline G4 (feed M.o. 800mg/kg weight of rat) & $8,238.02 \mathrm{ef} \pm 574.41$ & $3.36 \mathrm{~d} \pm 0.23$ \\
\hline G5 (feed M.o. 1000mg/kg weight of rat) & $9,720.00 \mathrm{ab} \pm 383.41$ & $4.37 \mathrm{a} \pm 0.17$ \\
\hline G6 (feed M.o. 1200mg/kg weight of rat) & $10,132.00 \mathrm{a} \pm 130.27$ & $4.56 \mathrm{a} \pm 0.06$ \\
\hline F & 122.421 & 212.008 \\
\hline Sig. & 0.000 & 0.000 \\
\hline
\end{tabular}

Values with the same letters by column indicate no significant difference $(p<0.05)$ and vice versa.

\section{2- Effect of gum Arabic and Moringa oleifera extracts on $\mathrm{pH}$ and volume of gastric juice.}

It was obvious from data in Table (3) that $\mathrm{pH}$ of gastric juice of rats in groups G1,G2 and G3 fed gum arabic extract was significantly increased when compared with $\mathrm{pH}$ value in positive control group $\left(\mathrm{G}^{+}\right)$with the highest value in $\mathrm{G} 3$. While it had significant decrease in G1, G2 and G3 when compared with negative control group $\left(\mathrm{G}^{-}\right)$. Aqueous extract of Moringa oleifera at the investigated doses caused significant increase in $\mathrm{pH}$ of gastric juice of rats in groups G4, G5 and G6 as compared with positive control group $\left(\mathrm{G}^{+}\right)$, while $\mathrm{pH}$ value had significant decrease in G4 and G5 and insignificant increase in G6 when compared with $\mathrm{pH}$ in gastric juice of the negative control group $\left(\mathrm{G}^{-}\right)$.
The volume of gastric juice in rats treated with gum Arabic doses was significantly decreased in rats of groups G1,G2 and G3 when compared with negative and positive control groups (G- and $\mathrm{G}+$, respectively) as indicated from Table (3). On the other hand, it was clear that volume of gastric juice in stomach of rats treated with $M$. oleifera extract increased in G5 and G6 and decreased in G4 when compared with positive control group $\left(\mathrm{G}^{+}\right)$, while it was significantly decreased in G4 and increased in G5 and G6 when compared with negative control group $\left(\mathrm{G}^{-}\right)$. The highest significant increase in volume of gastric juice was found in G6 as shown in Table (3). 


\section{Comparative study on the effectiveness of gum arabic Acacia senegal and Moringa oleifera extracts on prevention of peptic ulcer in the experimental rats}

Table 3: Effect of gum arabic and Moringa oleifera extracts on $\mathrm{pH}$ and gastric juice volume in stomach of investigated rats.

\begin{tabular}{|l|c|c|}
\hline \multicolumn{1}{|c|}{ Treat } & $\mathrm{pH}$ & Volume $\left(\mathrm{cm}^{3}\right)$ \\
\cline { 2 - 3 } & Mean $\pm \mathrm{SD}$ & Mean $\pm \mathrm{SD}$ \\
\hline$\left(\mathrm{G}^{+}\right)$Control Positive & $1.69 \mathrm{f} \pm 0.08$ & $1.34 \mathrm{c} \pm 0.04$ \\
\hline$\left(\mathrm{G}^{-}\right)$Control Negative & $2.80 \mathrm{a} \pm 0.10$ & $1.26 \mathrm{~d} \pm 0.04$ \\
\hline $\mathrm{G} 1$ (feed GA 500mg/kg weight of rat) & $2.07 \mathrm{e} \pm 0.07$ & $0.99 \mathrm{~g} \pm 0.03$ \\
\hline G2 (feed GA 1000mg/kg weight of rat) & $2.51 \mathrm{c} \pm 0.24$ & $1.20 \mathrm{de} \pm 0.12$ \\
\hline G3 (feed GA 1500mg/kg weight of rat) & $2.70 \mathrm{ab} \pm 0.08$ & $1.21 \mathrm{de} \pm 0.04$ \\
\hline G4 (feed M.o. 800mg/kg weight of rat) & $2.44 \mathrm{c} \pm 0.17$ & $1.09 \mathrm{f} \pm 0.08$ \\
\hline G5 (feed M.o. 1000mg/kg weight of rat) & $2.72 \mathrm{a} \pm 0.11$ & $2.43 \mathrm{~b} \pm 0.10$ \\
\hline G6 (feed M.o. 1200mg/kg weight of rat) & $2.84 \mathrm{a} \pm 0.04$ & $2.53 \mathrm{a} \pm 0.03$ \\
\hline F & 41.841 & 401.133 \\
\hline Sig. & 0.000 & 0.000 \\
\hline
\end{tabular}

Values with the same letters by column indicate no significant difference $(\mathrm{p}<0.05)$ and vice versa.

\section{Histopathological results}

Microscopically, stomach of rats from control negative group revealed the normal histological structure of gastric layers (Fig. A). Stomach of rats from control positive group revealed mucosal inflammatory cells infiltration, submucosal oedema, congestion and inflammatory cells infiltration (Figs. B). Some examined sections from group 1 showed congestion of mucosal blood vessels and submucosal oedema (Fig. C). Stomach of rat from group 2 showing submucosal oedema, congestion and few inflammatory cells infiltration. (Fig. D). However, stomach of rats from group 3 showed slight submucosal oedema (Fig. E). Moreover, stomach of rat from group
4 showing congestion of submucosal blood vessels and submucosal oedema. (Fig. F). Stomach of rat from group 5 showing slight submucosal oedema (Fig. G). Stomach of rat from group 6 showing no histopathological changes. (Fig. H).

On the other hand, Stomach of rat from group 7 showing focal necrosis of the mucosa, mucosal haemorrhage and submucosal inflammatory cells infiltration (Fig. J). Sections from stomach of rat from group 8 showing focal necrosis of the mucosa associated with inflammatory cells infiltration and submucosal oedema. (Fig. K). Stomach of rat from group 9 showing focal necrosis of the mucosa, and submucosal inflammatory cells infiltration. (Fig. L). 
Ekbal M.M. Saleh et al.

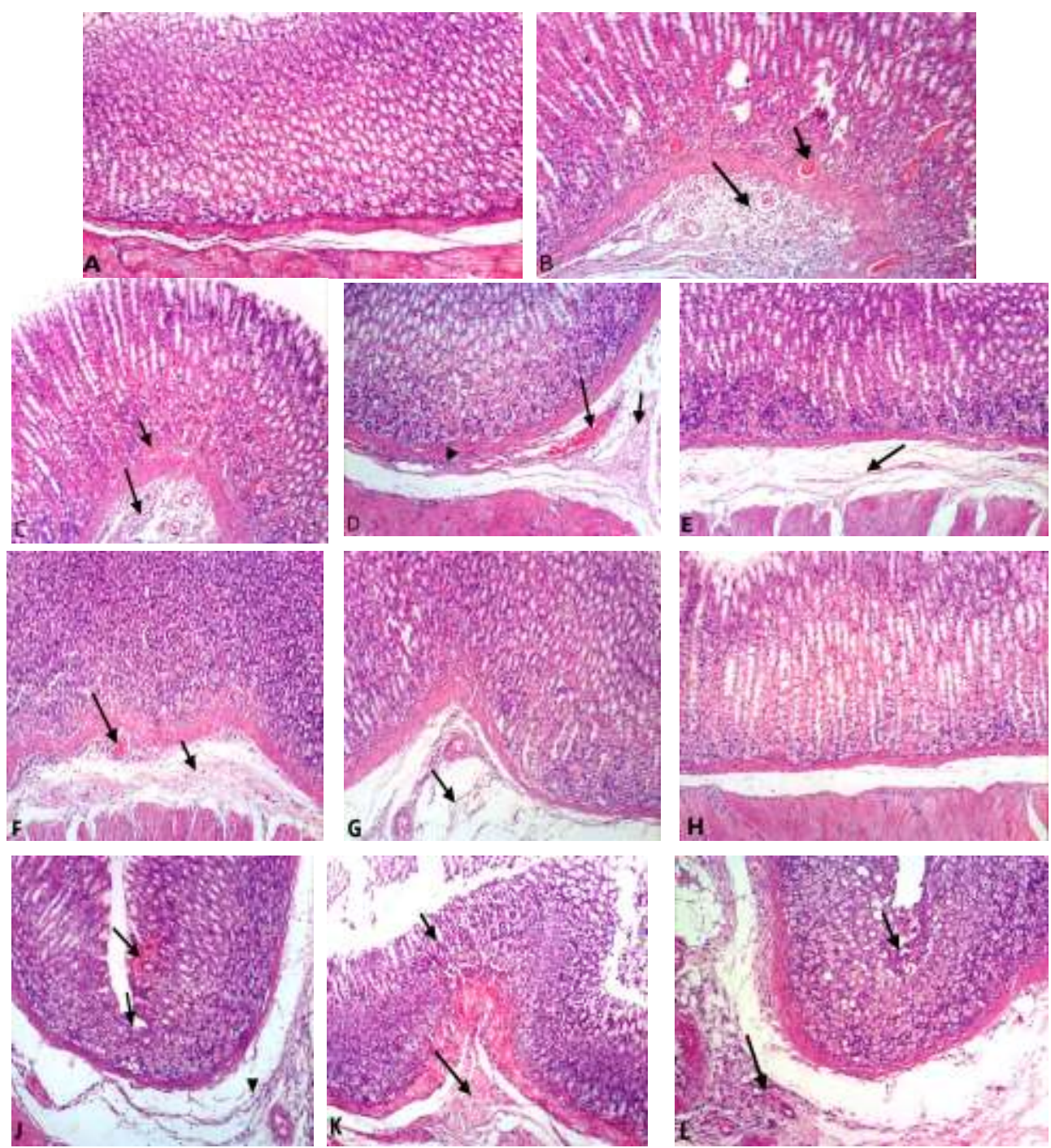

Figs. A-L. T.S. of stomach of rat. Stained Hx-E, X 100

Fig. (A): Control Negative group showing the normal histological structure of gastric layers.

Fig. (B): Control Positive group showing congestion of mucosal blood vessels (small arrow) and submucosal oedema with inflammatory cells infiltration (large arrow).

Fig. (C): Group $1 \mathrm{AG}(500 \mathrm{mg} / \mathrm{kg})$ showing congestion of mucosal blood vessels (small arrow) and submucosal oedema (large arrow).

Fig. (D): Group 2AG (1000 mg/kg) showing submucosal oedema (small arrow), congestion (large arrow) and few inflammatory cells infiltration (arrow head).

Fig. (E): Group 3 AG $(1500 \mathrm{mg} / \mathrm{kg}$ ) showing slight submucosal oedema (arrow).

Fig. (F): Group 4M $(800 \mathrm{mg} / \mathrm{kg})$ showing congestion of submucosal blood vessels (small arrow) and submucosal oedema (large arrow).

Fig. (G): Group 5M (1000mg/kg) showing slight submucosal oedema (arrow).

Fig. (H): G group 6M (1200mg/kg) showing no histopathological changes.

Fig. (J): Group7 M\&AG $(500 \mathrm{mg} / \mathrm{kg})$ showing focal necrosis of the mucosa (small arrow), mucosal haemorrhage (large arrow) and submucosal inflammatory cells infiltration (arrow head).

Fig. (K): Group8 M\&AG (1000mg/kg) showing focal necrosis of the mucosa associated with inflammatory cells infiltration (small arrow) and submucosal oedema (large arrow).

Fig. (L): Group $9 \mathrm{M} \& \mathrm{AG}(1500 \mathrm{mg} / \mathrm{kg}$ ) showing focal necrosis of the mucosa (small arrow), and submucosal inflammatory cells infiltration (large arrow). 


\section{Comparative study on the effectiveness of gum arabic Acacia senegal and Moringa oleifera extracts on prevention of peptic ulcer in the experimental rats}

\section{Discussion}

Our finding showed that gum arabic aqueous extracts at the different tested doses $(500,1000,1500 \mathrm{mg} / \mathrm{kg})$ and moringa oleifera aqueous extracts at the different tested doses (800, 1000, 1200 $\mathrm{mg} / \mathrm{kg}$ ) had increased and improvement in WBC and lymphocytes when compere with those of positive control group $\left(\mathrm{Co}^{+}\right)$.It has a therapeutic effect on the peptic ulcers when using gum arabic dose $1000 \mathrm{mg} / \mathrm{kg}$ and moringa oleifera at dose of $800 \mathrm{mg} / \mathrm{kg}$. The rat's stomachs showed signs of improvement in peptic ulcers in most sections with use moringa oleifera at dose of $800,1200 \mathrm{mg} / \mathrm{kg}$. results are similar that obtained in animal models, in another recent study, two doses of gum arabic $(500,1000$ $\mathrm{mg} / \mathrm{kg}$ ) were found to exhibit antiulcer potentiality against acute indomethacinassociated ulceration in rats (AL-Yahya and Asad, 2016). In the same approach, treatment of rats with aspirin followed by gum Arabic ( $1 \mathrm{~g} / \mathrm{kg} /$ day) for 21 days revealed remarkable preservation of gastric mucosa (Nasif, et al., 2011). The role of gum arabic in preventing gastric injury may be explained in terms of the antioxidant capacity of its constituents in protecting the cells from the injurious effect of ROS (AL-Yahya and Asad, 2016).

Ari-egoro, et al. (2019) showed that moringa oleifera at $37.5 \mathrm{~g}, 56.0 \mathrm{~g}$ and $75.0 \mathrm{~g}$ caused increase in the level of lymphocyte count in all the test groups. This observation showed the function of differential white blood cell (Lymphocyte) to fight against invading microorganisms. This study suggests that the consumption of moringa oleifera leaves at small quantity seems better. Lymphocytes are produced naturally by the body system in response to any foreign substances in the body. In order to avoid induction of lymphocytes, minimum quantities which are sufficient to perform the nutritional and/or therapeutic function by which it is used for must be taken into consideration during consumption.

Also, none of the doses tested at moringa oleifera $(800,1000,1200 \mathrm{mg} / \mathrm{kg})$ produced any gross apparent effect on general motor activity, muscular weakness, fecal output, feeding behavior etc., not cause any mortality in rats. These results are in agreement with those of Vinay et al. (2012), study found that $50 \%$ ethanolic leaves extract of moringa oleifera up to $2000 \mathrm{mg} / \mathrm{kg}$ did not cause any mortality in rats. None of the doses tested produced any gross apparent effect on general motor activity, muscular weakness, fecal output, feeding behaviour etc. during the period of observation.

Gum arabic and moringa oleifera showed improvement in reduction volume of gastric juice and increase $\mathrm{pH}$, tetrable acidity and total acid output of gastric juice of rats and the group which treated gum arabic showed more effective in improvement. These results are in agreement with those obtained by Abeer, (2017) who showed that rats fed gum arabic powder (GAP) were effective to reducing the ulcer scor, ulcer index, \% ulceration and the $10 \%$ (GAP) was more effective. Also, Abdulrahman and Mohammed (2016): found that gum arabic at both tested doses orally produce significant reduction in the ulcer index; Also, Devaraj et al. (2007): who found that Healing of indomethacin-induced gastric ulcers the acetone and methanol leaf extracts of moringa oleifera showed a significant reduction in ulcer index and a significant increase in mucus content when compared with that of control. Stress-induced gastric ulcers all the three leaf extracts of moringa oleifera showed a significant reduction in 


\section{Ekbal M.M. Saleh et al.}

ulcer index when compared with those of control. Again, the acetone extract of the leaves was most potent in reducing ulcer index.

\section{Conclusion}

The present findings concluded that water extracts of gum arabic and moringa oleifera had treatment effect on peptic ulcer. Moringa oleifera extracts were more superior to gum arabic in its treatment and improvement of the stomach. The ratios used for gum arabic and moringa oleifera to treat and improve stomach ulcers did not result in any negative effects.

\section{REFERENCES}

Abdulrahman, A.I.; AL-Yahya, A. and Mohammed, A. (2016). Antiulcer activity of gum Arabic and its interaction with antiulcer effect of ranitidine in rats. Biomed. Res., 27 (4): 1102-1106.

Abeer, A.K. (2017). Antiulcer protective activity of gum Arabic (Acacia Senegal) in adult rats. Bull. Nat. Nutr. Inst. Arab Republic of Egypt. June 2017(49): 1.

Agrawal, A.; Roo, V.; Sairam, K.; Joshi, V. and Goel, R. (2000). Effect of piper longgum linn, Zingiber officinale linn and ferule species on gasric ulceration and secretion in rat. Exper. Biol.,38: 994-998.

Akomas, S.C.; Ezeifeka, G.O. and Ijioma, S.N. (2014). Justification for the use of Musa paradisiaca fruit extract for GIT mucosa protection and ulcer treatment. Cont J. Anim Vet Res.,, 6(1):2935.

Al-dalain, S.; El-kutry, M. and Ibrahim, H. (2008. Inhibitory effect of aqueous extracts of barley and fenugreek on ulcer induction in rats. World Appl. Sci. J., 15(3): 332-339.
Ali, B.H.; Al Za'abi, M.; Al Shukaili, A. and Nemmar, A. (2015). High mobility group box-1 protein in adenine-induced chronic renal failure and the influence of gum Arabic thereon. Physiol. Res., 64: 147- 151.

AL-Yahya, A.A. and Asad, M. (2016). Antiulcer activity of gum Arabic and its interaction with antiulcer effect of ranitidine in rats. Biomed. Res., 27: 1102-1106.

Ari-egoro, Y.E.; Ayodele, P.F. and Oyeleke, O.M. (2019). Effects of Graded Levels of Moringa oleifera leaf-meal in albino rat diet on some hematological parameter. J. Anal. Tech. Res., 1(2): 037-046.

carleton, H. (1979). Histological technique", 4 th Ed, London, Oxford University Press, New York, USA, Toronto.

Devaraj, V.C.; Asad, M. and Prasad, S. (2007). Effect of leaves and fruits of Moringa oleifera on gastric and duodenal ulcers. Pharm. Biol. 45(4):332-338.

Gado, A.M. and Aldahmash, B.A. (2013). Antioxidant effect of gum arabic against mercuric chloride induced nephrotoxicity. Drug Des Devel Ther, 7: 12451252.

Gohar, A.A. and Zaki, A.A. (2014). Assessment of some herbal drugs for prophylaxis of peptic ulcer. Iran J. Pharm. Res., 13:10811086.

Hegested, D.M.; Mills, R.C.; Elvehijem, C.A. and Hart, F.B. (1941). Choline in the nutrition of check. J. Biol. Chem., 138:459.

Hemamalini, K.; Lavanya, C.H.; Anurag, B. and Uma, V. (2012). Anti-ulcer activity of methanolic 
Comparative study on the effectiveness of gum arabic Acacia senegal and Moringa oleifera extracts on prevention of peptic ulcer in the experimental rats

extracts of Wattakaka volubilis and Tabebula rosea in rats. Asian J. Pharm, Clin. Res., 5(3):242246.

Kassi, E.; Papoutsi, Z. and Fokialakis, N. (2004). Greek plant extracts exhibit selective estrogen receptor modulator (SERM) like properties. J. Agric. Food Chem. 52:6956-6961.

Milosavljevic, T.; Kostić-Milosavljević, M.; Jovanović, I. and Krstić, M. (2011). Complications of peptic ulcer disease. Dig. Dis., 29:491493.

Najm, W.I. (2011). Peptic ulcer disease. Primary Care, 38(3):383-94.

Nasir, O. (2013). Renal and extra-renal effects of gum Arabic (Acacia senegal)-what can be learned from animal experiments? Kidney Blood Press Res., 37: 269-79.

Nasir, O.; Wang, K.; Föller, M.; Bhandaru, M.; Sandulache, D.; and Artunc, F. (2010). Down regulation of angiogenin transcript levels and inhibition of colonic carcinoma by gum arabic (Acacia senegal). Nutr. Cancer,62:.802-10.

Nasir, O.; Artunc, F.; Wang, K.; Rexhepaj, R.; Föller, M.; Ebrahim, A.; Kempe, D.S.;
Biswas, R.; Bhandaru, M.; Walter, M.; Mohebbi, N.; Wagner, C.A., Saeed, A.M. And Lang, F. (2010). Down regulation of mouse intestinal $\mathrm{Na}$ $(+)$ - coupled glucose transporter SGLT1 by gum arabic (Acacia senegal). Cell Physiol. Biochem., 25:203-210.

Osim, E.E., (2002). Elements of gastrointestinal tract physiology. Calabar: Helimo Associates Publishers, pp. 87-88.

Sasmal, D.; Das, S. and Basu, S.P., (2007). Phytoconstituents and therapeutic potential of Nyctanthes arbortristis Lin. Pharmacol. Rev., 1: 344-49.

Vinay K.V.; Nripendra, S.; Puja, S. and Ritu, S. (2012). Anti-ulcer and antioxidant activity of Moringa oleifera (Lam) leaves against Aspirin and Ethanol induced gastric ulcer in rats. Int. Res. J. Pharmaceut., 2(2): 46-57.

Zelickson, M.S.; Bronder, C.M.; Johnson, B.L.; Camunas, J.A.; Smith, D.E.; Rawlinson, D.; Von. S.; Stone, H.H. and Taylor, S.M. (2011). Helicobacter pylori is not the predominant etiology for peptic ulcers requiring operation. Am. Surg. 77:1054-1060. 


\section{Ekbal M.M. Saleh et al.}

دراسة مقارنة على فعالية مستخلصات الصمغ العربي والمورينجا على القرحة الهضمية في فئران التجارب

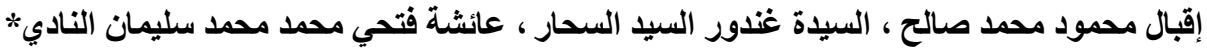

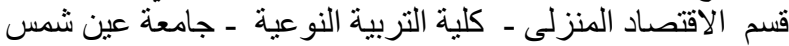

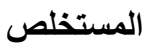

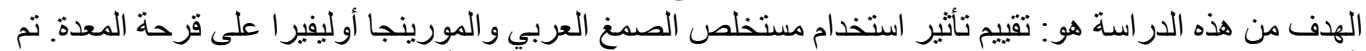

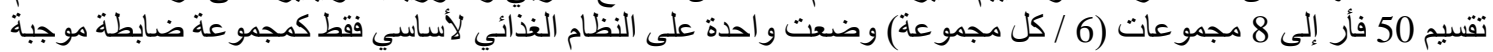

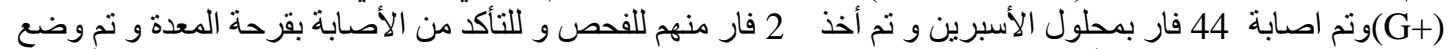

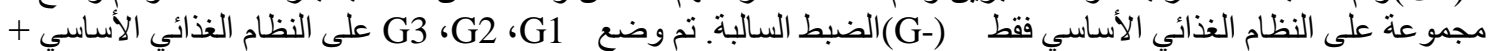

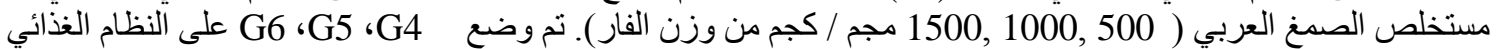

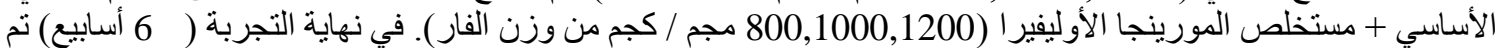

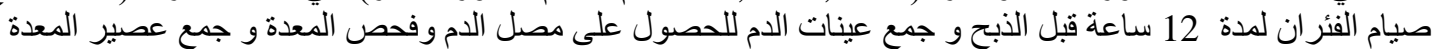

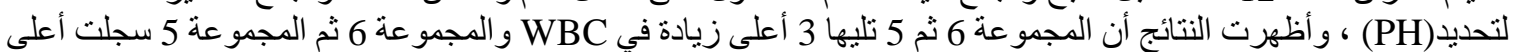

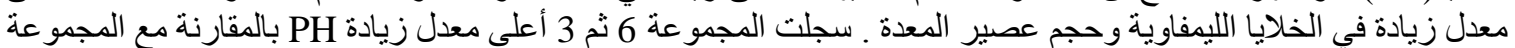

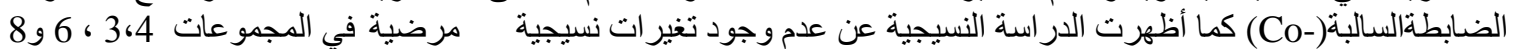

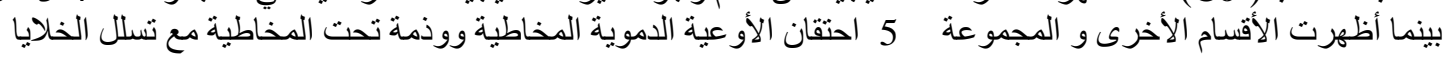

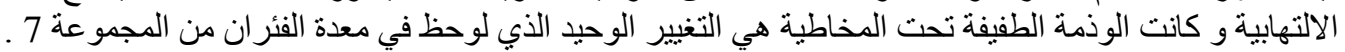

